\title{
An Effective Method for Initialization of Lloyd-Max's Algorithm of Optimal Scalar Quantization for Laplacian Source
}

\author{
Zoran PERIC, Jelena NIKOLIC \\ Faculty of Electronic Engineering, University of Nis \\ Aleksandra Medvedeva 14, 18000 Nis, Serbia and Montenegro \\ e-mail:peric@elfak.ni.ac.yu,njelene@elfak.ni.ac.yu
}

Received: September 2006

\begin{abstract}
In this paper an exact and complete analysis of the Lloyd-Max's algorithm and its initialization is carried out. An effective method for initialization of Lloyd-Max's algorithm of optimal scalar quantization for Laplacian source is proposed. The proposed method is very simple method of making an intelligent guess of the starting points for the iterative Lloyd-Max's algorithm. Namely, the initial values for the iterative Lloyd-Max's algorithm can be determined by the values of compandor's parameters. It is demonstrated that by following that logic the proposed method provides a rapid convergence of the Lloyd-Max's algorithm.
\end{abstract}

Key words: initialization, Lloyd-Max's algorithm, scalar quantizers.

\section{Introduction}

Quantizers play an important role in theory and practice of modern day signal processing. A vast amount of research has been made in the area of quantization. One of the most important issues from the engineer's point of view is the design and implementation of quantizers to meet the performance objectives. Lloyd (1982) and Max (1960) independently proposed an algorithm to compute optimum quantizers using mean-square error distortion measure. The algorithm is widely used in practice because it can be easily implemented. It is frequently called in literature the Lloyd-Max's I algorithm to distinguish it from the second algorithm. Namely, Lloyd developed the second algorithm for the scalar quantizers, known as Lloyd-Max's II algorithm (Wu, 1990). These two algorithms differ in regard to stopping criteria that interrrupts the algorithm. Namely, the Lloyd-Max's I algorithm stops when further iteration no longer produce any changes in distortion or changes are below the suitable threshold, while Lloyd-Max's II algorithm stops when suggested absolute accuracy of the last representation level is achieved. Here, we consider Lloyd-Max's I algorithm and propose choosing of initial values by determinig them when nonuniform scalar quantizer is realised by using companding technique. The stopping criteria used in this paper compares the value of relative disortion error with small constant 0.005 . Accordingly, interruption of the Lloyd-Max's algorithm 


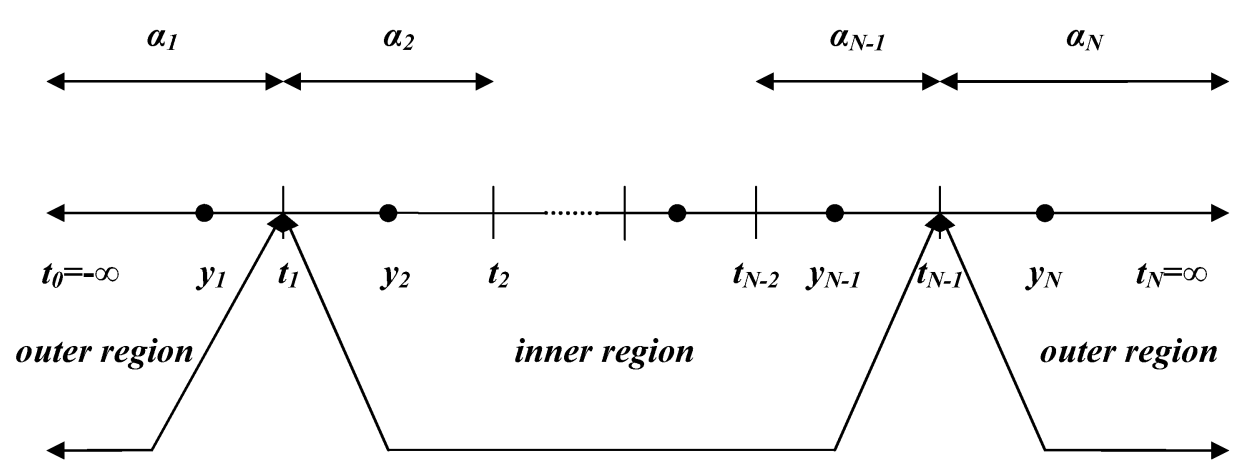

Fig. 1. Illustration of the inner region and the outer region of the scalar quantizer.

is allowed if the value of relative disortion error is below the given threshold. A great number of researchers has been occupied by the Lloyd-Max's algorithm initialization problem (Wu, 1990). Different techniques were proposed to obtain better initial conditions of the Lloyd-Max's algorithm in order to improve its convergence speed. The initial conditions suggested in this paper are easily obtained and they contribute to a rapid convergence of the Lloyd-Max's algorithm.

\section{Nonuniform Scalar Quantization}

Let an $N$-level scalar quantizer $Q$ be characterized in terms of a set of $N$ real-valued quantization points, i.e., representation levels $\left\{y_{1}, y_{2}, \ldots, y_{N}\right\}$ and decision thresholds $\left\{t_{0}, t_{1}, \ldots, t_{N}\right\}$, shown in Fig. 1 . The negative thresholds and representation levels are symmetric to their nonnegative counterparts:

$$
t_{0}=-\infty<t_{1}<\ldots<t_{N-1}<t_{N}=\infty
$$

Decision thresholds are used to define the cells for the quantizer, which are given by:

$$
\alpha_{j}=\left(t_{j-1}, t_{j}\right], \quad j=1,2, \ldots, N
$$

Cells $\alpha_{2}, \ldots, \alpha_{N-1}$ are referred to as the inner cells, while $\alpha_{1}$ and $\alpha_{N}$ are referred to as the outer cells. Cells that are unbounded $\left(t_{0}=-\infty\right.$ and $\left.t_{N}=\infty\right), \alpha_{1}$ and $\alpha_{N}$, are called overload cells, while cells that are bounded, $\alpha_{2}, \ldots, \alpha_{N-1}$, are called granular cells. The collection of all overload cells is called the overload region, while collection of all granular cells is called the granular region. A quantized signal has value $y_{j}$ when the original signal belongs to the quantization cell $\alpha_{j}$. Hence, $N$-level scalar quantizer is defined as a functional mapping of an input value $x$ onto an output representation, such that:

$$
Q(x)=y_{j}, \quad x \in \alpha_{j}
$$




\section{The Quantizer Distortion}

The quality of a quantizer can be measured by the distortion of the resulting reproduction in comparison to the original. The most convenient and widely used measure of distortion between the input signal $x$ and the quantized signal $y_{j}$ is the average mean-squared error, i.e., quantization noise. If a quantizer is optimal, then no other $N$-level scalar quantizer can provide lower distortion. We can consider that total distortion consists of two components, inner $D_{i}$ and outer distortion $D_{0}$, defined as:

$$
\begin{aligned}
D_{i} & =\sum_{j=1}^{N-2} \int_{t_{j}}^{t_{j+1}}\left(x-y_{j+1}\right)^{2} p(x) \mathrm{d} x, \\
D_{o} & =2 \int_{t_{N-1}}^{\infty}\left(x-y_{N}\right)^{2} p(x) \mathrm{d} x, \\
D & =\sum_{j=1}^{N-2} \int_{t_{j}}^{t_{j+1}}\left(x-y_{j+1}\right)^{2} p(x) \mathrm{d} x+2 \int_{t_{N-1}}^{\infty}\left(x-y_{N}\right)^{2} p(x) \mathrm{d} x .
\end{aligned}
$$

The primary goal when designing an otimal Lloyd-Max's quantizer is to select the representation levels and decision thresholds so as to provide the minimum possible average distortion for a fixed number of quantization levels $N$. Considerable amount of work has been focused on the design of optimal quantizers for compression sources in image, speech, and other applications. The sources with exponential and Laplacian probability density functions are commonly encountered and the methods for designing quantizers for these sources are very similar. In this paper we consider the Laplacian input signals with unrestricted amplitude range. Laplacian probability density function (pdf) of the original random variable $x$ with unit variance can be expressed by:

$$
p(x)=\frac{\sqrt{2}}{2} e^{-|x| \sqrt{2}} .
$$

Here, we consider the case when there is no restriction in ampltude of input signal. Optimal maximal amplitude of the input signal is required when designing of an optimal scalar quantzer. Its determination exists as a current problem which was considered before in (Na, 2004; Na and Neuhoff, 2001).

While working (Peric et al., 2005) we derived the expression for determining the value of the decision threshold $t_{N-1}$, denoted here as $t_{N-1}^{c o m}$, when the observed quantizer was realised by using the companding technique:

$$
t_{N-1}^{c o m}=\frac{3}{\sqrt{2}} \ln \left(\frac{N}{2}\right) .
$$

Using the well known fact that the width of the last cell $\alpha_{N}$ for Lloyd-Max's quantizers is $\sqrt{2}$ (Na, 2004; $\mathrm{Na}$ and Neuhoff, 2001; Peric et al., 2005) we can estimate the initial value of the maximal amplitude of the input signal, denoted here as $t_{\max }^{\text {com }}$, assuming that 
the width of the last cells for Lloyd-Max's quantizer and nonuniform quantizer, realised by using companding technique, are equal.

$$
t_{\max }^{c o m}=\frac{3}{\sqrt{2}} \ln \left(\frac{N}{2}\right)+\sqrt{2}
$$

This value of the maximal input signal is needed when determining the values of the decision thresholds and the representation levels of nonuniform scalar quantizer, which is realised by using companding technique. The values of decision thresholds and the representation levels calculated in such a way can be used as initial values for the LloydMax's algorithm.

\section{Companding Technique}

In this paper, the commonly used nonlinear quantization scheme (Judell and Scharf, 1986), Fig. 2., is analyzed. This scheme forms the core of the ITU-T G.711 PCM standard, recommended for coding speech signals. Namely, here we consider nonuniform scalar quantizers based on the companding technique. Nonuniform quantization can be achieved by the following procedure: compress the signal $x$ using nonlinear compressor characteristic $c(\cdot)$, quantize the compressed signal $c(x)$ with a uniform quantizer, expand the quantized version of the compressed signal using a nonlinear transfer characteristic $c^{-1}(\cdot)$ inverse to that of the compressor as in Fig. 2. The corresponding structure of a nonuniform quantizer consisting of a compressor, a uniform quantizer, and expandor in cascade is called compandor.

Let us define the compressor function $c(x)$ similar as in (Judell and Scharf, 1986):

$$
\begin{aligned}
& c\left(t_{j}\right)=-t_{\max }+2 t_{\max } \frac{\int_{-t_{\max }}^{t_{j}} p^{1 / 3}(x) \mathrm{d} x}{\int_{-t_{\max }}^{+t_{\max }} p^{1 / 3}(x) \mathrm{d} x} \\
& c\left(y_{j}\right)=-t_{\max }+2 t_{\max } \frac{\int_{-t_{\max }}^{y_{j}} p^{1 / 3}(x) \mathrm{d} x}{\int_{-t_{\max }}^{+t_{\max }} p^{1 / 3}(x) \mathrm{d} x} .
\end{aligned}
$$

Also, the following equations are valid for the compressor function $c(x)$ (Jayant and Noll, 1984):

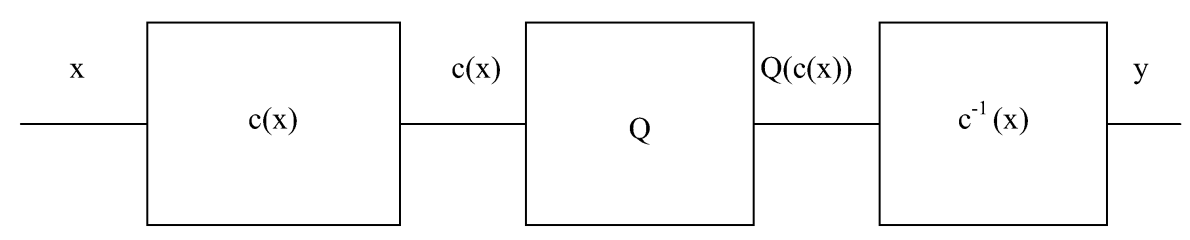

Fig. 2. Block diagram of companding technique. 


$$
\begin{aligned}
& c\left(t_{j}\right)=-t_{\max }+\frac{2 j}{N} t_{\max } \\
& c\left(y_{j}\right)=-t_{\max }+\frac{2(j-1 / 2)}{N} t_{\max } .
\end{aligned}
$$

Decision thresholds $t_{j}, j=1,2, \ldots, N-1$ and the representation levels $y_{j}, j=$ $1,2, \ldots, N$ can be determined by combining the last four equations:

$$
\begin{aligned}
t_{j}= & \frac{3}{\sqrt{2}} \ln \left(\frac{2 j+(N-2 j) \exp \left(-\frac{\sqrt{2}}{3} t_{\max }\right)}{N}\right) \quad t_{j}<0,1 \leqslant j \leqslant \frac{N}{2} \\
y_{j}= & \frac{3}{\sqrt{2}} \ln \left(\frac{2 j-1+(N-2 j+1) \exp \left(-\frac{\sqrt{2}}{3} t_{\max }\right)}{N}\right) \quad y_{j}<0,1 \leqslant j \leqslant \frac{N}{2} \\
t_{j}= & \frac{3}{\sqrt{2}} \ln \left(\frac{N}{2 N-2 j+(2 j-N) \exp \left(-\frac{\sqrt{2}}{3} t_{\max }\right)}\right) t_{j}>0, \frac{N}{2}<j<N \\
y_{j}= & \frac{3}{\sqrt{2}} \ln \left(\frac{N}{2 N-2 j+1+(2 j-1-N) \exp \left(-\frac{\sqrt{2}}{3} t_{\max }\right)}\right) \\
& y_{j}>0, \frac{N}{2}<j \leqslant N .
\end{aligned}
$$

The values of decision thresholds $\left\{t_{1}, t_{2}, \ldots, t_{N-1}\right\}$ and the representation levels $\left\{y_{1}, y_{2}, \ldots, y_{N}\right\}$ of nonuniform scalar quantizer, realised by using companding technique, are function of maximal amplitude of restricted input signal, $t_{\max }$. Using the value for $t_{\max }$ calculated in (9), i.e., $t_{\max }^{\text {com }}$, from (14), (15), (16) and (17) we can calculate initial values for starting the Lloyd-Max's algorithm. Namely, due to the symmetry of the parameters of the $N$-level nouniform scalar quantizer it is sufficient to calculate only one-sided decision thresholds and representation levels using (16) and (17).

\section{Lloyd-Max-ov Algorithm}

Max (1960) showed that the optimum decision levels are half-way between the neighboring representation levels. He also showed that representation levels should be the centroid of the probability density function in the appropriate interval. Lloyd-Max's algorithm for designing optimal scalar quantizers (Max, 1960; Jayant and Noll, 1984), starts with an estimate of the decision thresholds and the representation levels, and the convergence is better if the estimate is better. Here, we calculate the initial values for starting the LloydMax's algorithm by using (16) and (17) when the value of the maximal amplitude of input signal is $t_{\max }^{c o m}$. By using (6), distortion, denoted $D^{\operatorname{com}(0)}$ can be calculated. The important fact is that the values for the thresholds $t_{0}$ and $t_{N}$ are unchangeable $\left(t_{0}=-\infty\right.$ and $\left.t_{N}=\infty\right)$, and there is no need to calculate them again by using Lloyd-Max algorithm. However, they are indispensable when determining the representation levels $y_{1}$ and $y_{N}$. 
Lloyd-Max's algorithm consists of following steps:

Step 1 . The iterative process starts for $i=0$, and the initial values for the decision thresholds $\left\{t_{1}^{(0)}, t_{2}^{(0)}, \ldots, t_{N-1}^{(0)}\right\}$ and the representation levels $\left\{y_{1}^{(0)}, y_{2}^{(0)}, \ldots, y_{N}^{(0)}\right\}$ are taken from:

$$
\begin{aligned}
t_{j}^{(0)}= & \frac{3}{\sqrt{2}}\left(\ln \left(\frac{N}{2 N-2 j+(2 j-N) \exp \left(-\frac{\sqrt{2}}{3} t_{\max }^{c o m}\right)}\right)\right. \\
& t_{j}^{(0)}>0, \frac{N}{2}<j<N, \\
y_{j}^{(0)}= & \frac{3}{\sqrt{2}} \ln \left(\frac{N}{2 N-2 j+1+(2 j-1-N) \exp \left(-\frac{\sqrt{2}}{3} t_{\max }^{\text {com }}\right)}\right) \\
& y_{j}^{(0)}>0, \frac{N}{2}<j \leqslant N,
\end{aligned}
$$

and are used for calculating the initial values for the distortions $D^{\operatorname{com}(0)}$.

Step 2. Iteratively determining of new values for the decision thresholds and the representation levels using following relations:

$$
\begin{aligned}
t_{j}^{(i+1)} & =\frac{\left(y_{j}^{(i)}+y_{j+1}^{(i)}\right)}{2} \quad 1 \leqslant j<N, \\
y_{j}^{(i+1)} & =\frac{\int_{t_{j-1}^{(i+1)}}^{t_{(i+1)}} x p(x) \mathrm{d} x}{\int_{t_{j-1}^{(i+1)}}^{t_{j}^{(i+1)}} p(x) \mathrm{d} x} \quad 1 \leqslant j \leqslant N .
\end{aligned}
$$

Step 3. Calculation of new distortion's value $D^{\operatorname{com}(i+1)}$ as well as value of the relative distortion errors $\delta^{\operatorname{com}(i)}$ :

$$
\delta^{\operatorname{com}(i)}=\frac{D^{\operatorname{com}(i+1)}-D^{\operatorname{com}(i)}}{D^{\operatorname{com}(i)}} .
$$

Step 4. Checking of the stopping criteria (Gray, 2004):

$$
\delta^{\operatorname{com}(i)}<0.005
$$

if the algorithm break is satisfied, if not back to Step 2. and repeating the algorithm to the stopping criteria.

The performance of a quantizer is often specified in terms of signal-to-noise ratio $(S N R)$, given by (Chu, 2003):

$$
S N R=10 \log _{10}\left(\frac{\sigma^{2}}{D}\right)
$$


measured in decibels, with $\sigma^{2}$ denoting the variance of $x$. We assume here the unit variance input signal, therefore $S N R$ can be given by:

$$
S N R=10 \log _{10}\left(\frac{1}{D}\right)
$$

In analyzing the behavior of the quantizer, it is preferable to use relative quantities, like signal-to-noise ratio instead of absolute quantities, such as distortion. Relative parameters portray the behavior of the quantizer in a way that is independent of the signal level and hence is more general. Let us denote the signal to noise ratio with $S N R^{\operatorname{com}(2)}$, when the value of the distortion is $D^{\operatorname{com}(2)}$. Also, let us denote with $S N R^{o p t}$ the optimal value for $S N R$. Numerical values of $S N R^{\text {opt }}$ are given in (Jayant and Noll, 1984), when the number of quantization cells $N$ varies.

\section{Numerical Results}

Table 1 provides numerical values of the relative distortion errors $\delta^{\operatorname{com}(i)}$ that are calculated for two iterations, when the number of quantization levels varies $(N=$ 16, 32, 64, 128). From Table 1, it is obvious that the stopping criteria that is considered in this paper is satisfied after two iteratons for optimal scalar quantizers with small number of quantization levels, while the algorithm is interrrupted after only one iteration for optimal scalar quantizers with large number of quantization levels. It is therefore obvious that the sugessted method for Lloyd-Max algorithm initializtion enables a rapid convergence of the algorithm. Table 2 provides positive numerical values of the decision thresholds $t_{j}^{\operatorname{com}(i)}, j=8, \ldots 15$, that are calculated for two iterations, when the number of quantization levels is $N=16$. Numerical positive values of the decision thresholds, denoted here

Table 1

Numerical values of the relative distortion errors $\delta^{\operatorname{com}(i)}$, calculated for two iterations, when the number of quantization levels varies $(N=16,32,64,128)$

\begin{tabular}{ccccc}
\hline$N$ & 16 & 32 & 64 & 128 \\
\hline$\delta^{\operatorname{com}(1)}$ & 0.0178 & 0.0101 & 0.0054 & $2.771210^{-3}$ \\
$\delta^{\operatorname{com}(2)}$ & $3.285610^{-5}$ & $2.713410^{-5}$ & $2.122710^{-5}$ & - \\
\hline
\end{tabular}

Table 2

Numerical positive values of the decision thresholds $t_{j}^{\operatorname{com}(i)}, j=8, \ldots, 15$, calculated for two iterations, when the number of quantization levels is $N=16$

\begin{tabular}{lcccccccc}
\hline$i$ & $t_{8}^{\operatorname{com}(i)}$ & $t_{9}^{\operatorname{com}(i)}$ & $t_{10}^{\operatorname{com}(i)}$ & $t_{11}^{\operatorname{com}(i)}$ & $t_{12}^{\operatorname{com}(i)}$ & $t_{13}^{\operatorname{com}(i)}$ & $t_{14}^{\operatorname{com}(i)}$ & $t_{15}^{\operatorname{com}(i)}$ \\
\hline 0 & 0 & 0.2639 & 0.5654 & 0.9169 & 1.3384 & 1.8651 & 2.5673 & 3.6241 \\
1 & 0 & 0.2686 & 0.5716 & 0.9255 & 1.3513 & 1.8864 & 2.6089 & 3.7408 \\
2 & 0 & 0.2675 & 0.5716 & 0.9255 & 1.3513 & 1.8863 & 2.6085 & 3.7389 \\
\hline
\end{tabular}


Table 3

Optimal positive reference of the decision thresholds (Jayant and Noll, 1984)

$t_{j}^{o p t}, j=8, \ldots, 15$, when the number of quantization levels is $N=16$

\begin{tabular}{cccccccc}
\hline$t_{8}^{o p t}$ & $t_{9}^{\text {op }}$ & $t_{10}^{\text {opt }}$ & $t_{11}^{\text {opt }}$ & $t_{12}^{\text {opt }}$ & $t_{13}^{\text {opt }}$ & $t_{14}^{\text {opt }}$ & $t_{15}^{\text {opt }}$ \\
\hline 0 & 0.264 & 0.567 & 0.920 & 1.345 & 1.878 & 2.597 & 3.725 \\
\hline
\end{tabular}

Table 4

Numerical positive values of the representation levels $y_{j}^{\operatorname{com}(i)}, j=9, \ldots, 16$, calculated for two iterations, when the number of quantization levels is $N=16$

\begin{tabular}{ccccccccc}
\hline$i$ & $y_{9}^{\operatorname{com}(i)}$ & $y_{10}^{\operatorname{com}(i)}$ & $y_{11}^{\operatorname{com}(i)}$ & $y_{12}^{\operatorname{com}(i)}$ & $y_{13}^{\operatorname{com}(i)}$ & $y_{14}^{\operatorname{com}(i)}$ & $y_{15}^{\operatorname{com}(i)}$ & $y_{16}^{\operatorname{com}(i)}$ \\
\hline 0 & 0.1279 & 0.4093 & 0.7338 & 1.1172 & 1.5855 & 2.1872 & 3.0305 & 4.4511 \\
1 & 0.1258 & 0.4093 & 0.7338 & 1.1172 & 1.5854 & 2.1871 & 3.0299 & 4.4479 \\
2 & 0.1254 & 0.4087 & 0.7338 & 1.1172 & 1.5854 & 2.1870 & 3.0292 & 4.4460 \\
\hline
\end{tabular}

Table 5

Optimal positive reference of the representation levels (Jayant and Noll, 1984)

$y_{j}^{o p t}, j=9, \ldots, 16$, when the number of quantization levels is $N=16$

\begin{tabular}{llllllll}
\hline$y_{9}^{\text {opt }}$ & $y_{10}^{\text {opt }}$ & $y_{11}^{\text {opt }}$ & $y_{12}^{\text {opt }}$ & $y_{13}^{\text {opt }}$ & $y_{14}^{\text {opt }}$ & $y_{15}^{\text {opt }}$ & $y_{16}^{\text {opt }}$ \\
\hline 0.124 & 0.405 & 0.729 & 1.111 & 1.578 & 2.178 & 3.017 & 4.432 \\
\hline
\end{tabular}

$t_{j}^{o p t}, j=8, \ldots 15$, are given in Table 3. These values present optimal positive reference of the decision thresholds (Jayant and Noll, 1984) for an optimal scalar quantizer when the number of quantization levels is $N=16$ and Laplacian input signal is used. Table 4 lists numerical positive values of the representation levels $y_{j}^{\operatorname{com}(i)}, j=9, \ldots, 16$, that are calculated for two iterations, when the number of quantization levels is $N=16$. Similar as in Table 3, Table 5 presents optimal reference positive values of the representation levels (Jayant and Noll, 1984), denoted here $y_{j}^{o p t}, j=9, \ldots 16$, for an optimal scalar quantizer when the number of quantization levels is $N=16$ and Laplacian input signal is used. Table 6 lists the numerical values of the signal-to-noise ratio $S N R^{\operatorname{com}(2)}$ and $S N R^{o p t}$, when the number of quantization levels varies $(N=16,32,64,128)$. Considering Table 6 , one can notice that the calculated values for $S N R^{\operatorname{com}(2)}$ are almost identical to the appropriate optimal values of $S N R^{\text {opt }}$ (Jayant and Noll, 1984). Optimal, reference values of the decision thresholds and the representation levels are primarily of theoretical importance while distortion or relative distortion error is useful in practice when designing scalar quantizers. 


Table 6
$\begin{gathered}\text { Numerical values of the } S N R^{\operatorname{com}(2)} \text { and } S N R^{\text {opt }} \text { when the number } \\
\text { of quantization levels varies }(N=16,32,64,128)\end{gathered}$
\begin{tabular}{ccccc}
\multicolumn{6}{c}{64} & 128 \\
\hline$N$ & 16 & 32 & 64 & 35.6881 \\
\hline$S N R^{\text {com }(2)}$ & 18.1322 & 23.8695 & 29.7427 & 35.69 \\
$S N R^{\text {opt }}$ & 18.13 & 23.87 & 29.74 & 3 \\
\hline
\end{tabular}

\section{Conclusion}

The proposed method makes possible simple initialization of Lloyd-Max's algorithm. Choosing initial values for the iterative Lloyd-Max's algorithm by determinig them when nonuniform scalar quantizer is realised by using companding technique provides algorithm rapid convergence. The stopping criteria used in this paper compares values of relative disortion error with small constant 0.005. Interruption of the Lloyd-Max's algorithm is allowed if the values of the relative disortion error are below a given threshold. The results demonstrate that by using the proposed initialization the Lloyd-Max's algorithm for the scalar quantizer with a large number of quantization levels, the algorithm converges after only one iteration. Analysis presented in this paper has the practical importance since it could be of great help to engineers. Particularly, it provides fast and efficient design of optimal scalar quantizers that are used for source coding of speech (Chu, 2003) and images (Gersho and Gray, 1992).

\section{References}

Chu, W.C. (2003). Speech Coding Algorithms. John Wiley \& Sons, New Jersey. Chapter 6, pp. 161-165.

Gersho, A., R.M. Gray (1992). Vector Quantization and Signal Compression. Kluwer Academic, Norwell, Massachusetts. Chapter 5, Chapter 6, pp. 133-202.

Gray, R. (2004). Quantization and Data Compression, Lecture Notes. Stanford University.

Jayant, N.S., P. Noll (1984). Digital Coding of Waveforms. Prentice-Hall, New Jersey. Chapter 4, pp. 129-139.

Judell, N., and L. Scharf (1986). A simple derivation of Lloyd's classical result for the optimum scalar quantizer. IEEE Transactions on Information Theory, 32(2), 326-328.

Lloyd, S.P. (1982). Least squares quantization in PCM. Unpublished memo., Bell Lab. (1957); IEEE Transactions on Information Theory, Vol. IT-28. pp. 129-137.

Max, J. (1960). Quantizing for minimum distortion. IRE, Transactions on Information Theory, Vol. IT-6, 7-12.

$\mathrm{Na}, \mathrm{S}$. (2004). On the support of fixed-rate minimum mean-squared error scalar quantizers for a Laplacian source. IEEE Transactions on Information Theory, 50(5), 937-944.

Na, S., and D.L. Neuhoff (2001). On the support of MSE-optimal, fixed-rate, scalar quantizers. IEEE Transactions on Information Theory, 47(7), 2972-2982.

Peric, Z., J.R. Nikolic, D. Pokrajac (2005). Analysis of support region for Laplacian source's scalar quantizers. In IEEE Conference, Proc. TELSIKS, Nis. pp. 491-495.

Wu, X. (1990). On initialization of Max's algorithm for optimum quantization. IEEE Transactions on Communication, 38(10), 1653-1656. 
Z. Peric was born in Nis, Yugoslavia, in 1964. He received the BSc degree in electronics and telecommunications from the Faculty of Electronic Engineering, Nis, Serbia, Yugoslavia, in 1989, and MSc degree in telecommunications from the University of Nis, in 1994. He received the $\mathrm{PhD}$ degree from the University of Nis, also, in $1999 . \mathrm{He}$ is currently a professor at the Department of Telecommunications and vicedean of the Faculty of Electronic Engineering, University of Nis, Serbia. His current research interests include the information theory, source and channel coding and signal processing. He is particulary working on scalar and vector quantization techniques in speech and image coding. He was author and coauthor in over 100 papers in digital communications. Dr. Peric has been a reviewer for IEEE Transactions on Information Theory. He is a member Editorial Board of Journal "Electronics and Electrical Engineering" Zoran H. Peric is with the Faculty of Electronic Engineering, Nis, Serbia.

J. Nikolic was born in Prokuplje, Yugoslavia, in 1978. She received the BSc degree in telecommunications from the Faculty of Electronic Engineering, Nis, in 2003, and MSc degree in telecommunications from the University of Nis, in 2006. She is currently a research assistant on a Science Research Program, supported by Serbian government, on Faculty of Electronic Engineering in the Laboratory for Telecommunications under supervision of prof. Zoran Peric, since 2003. Her current research interests include the information theory, source and channel coding and signal processing. She is particulary working on scalar quantization techniques in speech and image coding. She was author and coauthor in over 20 papers in digital communications. Jelena R. Nikolic is with the Faculty of Electronic Engineering, Nis, Serbia.

\section{Efektyvus Lloyd-Max optimalaus skaliarinio kvantavimo algoritmo inicializacijos metodas Laplaso šaltiniui}

\section{Zoran PERIC, Jelena NIKOLIC}

Šiame straipsnyje yra atliekama Lloyd-Max algoritmo ir jo inicializacijos tiksli ir pilna analizè. Yra pasiūlytas Lloyd-Max optimalaus skaliarinio kvantavimo algoritmo inicializacijos metodas Laplaso šaltiniui. Tai labai nesudètingas metodas, atliekantis intelektualų iteratyvaus Lloyd-Max algoritmo pradinių reikšmiu spėjimą. Konkrečiai, pradinès reikšmès iteratyviam Lloyd-Max algoritmui gali būti nustatytos pagal kodavimo-dekodavimo parametrų reikšmes. Yra parodyta, kad, sekant šią logiką, pasiūlytas metodas užtikrina greitą Lloyd-Max algoritmo konvergavimą. 